\title{
Ferulic acid pretreatment alleviates heat stress in blueberry seedlings by inducing antioxidant enzymes, proline, and soluble sugars
}

\author{
Z.-Y. CHENG ${ }^{1 \mathrm{a}}$, L. $\mathrm{SUN}^{2 \mathrm{a}}$, X.-J. WANG ${ }^{1 \mathrm{a}}$, R. $\mathrm{SUN}^{3 \mathrm{a}}$, Y.-Q. AN ${ }^{1}$, B.-L. $\mathrm{AN}^{1}$, M.-X. ZHU ${ }^{1}$, C.-F. ZHAO ${ }^{1}$, \\ and J.-G. BAI ${ }^{1 *}$
}

State Key Laboratory of Crop Biology, College of Life Sciences, Shandong Agricultural University, Tai'an, Shandong, 271018, P.R. China ${ }^{1}$

Economic Forest Research Institute, Shandong Academy of Forestry, Ji'nan, Shandong, 250014, P.R. China 2

School of Food Science and Engineering, Qilu University of Technology (Shandong Academy of Sciences), Ji'nan, Shandong, 250353, P.R. China ${ }^{3}$

\begin{abstract}
Heat causes stress in blueberry; therefore, the present study aimed to investigate whether exogenous ferulic acid (FA) might protect plants against heat stress and to analyze possible mechanisms underlying such protection. Blueberry (Vaccinium corymbosum) seedlings were pretreated with $0.6 \mathrm{mM}$ FA for $1 \mathrm{~d}$ and then kept at normal $\left(25 / 20{ }^{\circ} \mathrm{C}\right)$ or elevated $\left(39 / 30^{\circ} \mathrm{C}\right)$ temperatures for $3 \mathrm{~d}$. One day of FA pretreatment increased transcriptions of genes encoding iron superoxide dismutase, cytoplasmic copper/zinc superoxide dismutase, guaiacol peroxidase, ascorbate peroxidase, and glutathione reductase and elevated content of proline and soluble sugars in leaves. When the FA-pretreated blueberries were exposed to heat, transcriptions of these genes and content of proline and soluble sugars were higher than after heat treatment alone. Under heat, FA pretreatment also enhanced transcriptions of genes encoding chloroplast copper/zinc superoxide dismutase, catalase, glutathione peroxidase, monodehydroascorbate reductase, and dehydroascorbate reductase. This corresponds with increased activities of superoxide dismutase and glutathione peroxidase and is consistent with elevated content of ascorbate and glutathione in the FA-pretreated and heat-stressed blueberries. Compared with heat treatment alone, the combination of FA pretreatment and heat enhanced content of endogenous FA, decreased production of superoxide anion, and content of hydrogen peroxide and malondialdehyde, and also increased relative water content and osmotic potential in the leaves. Thus, pretreatment with FA mitigated the heat stress in the blueberries by elevating endogenous FA content, reducing accumulation of reactive oxygen species, and increasing proline and soluble sugar content.
\end{abstract}

Additional key words: ascorbate peroxidase, catalase, glutathione reductase, guaiacol peroxidase, malondialdehyde, superoxide dismutase, Vaccinium corymbosum.

\section{Introduction}

The high nutritional and economical values of blueberry fruits have made this plant important in many countries including China, where the northern highbush blueberry is widely cultivated in northern regions and has been introduced into the southeast (Chen et al. 2012). However, the optimum temperature of northern highbush blueberries is $23-25^{\circ} \mathrm{C}$ (Sun et al. 2007), and a rise in

the temperature of $10-15^{\circ} \mathrm{C}$ above the optimum often occurs during summer in China indicating that blueberries are subjected to heat stress (Wahid et al. 2007).

Heat stress has adverse effects on plant growth (Huang and $\mathrm{Xu}$ 2008). In addition, heat stress results in disruption of osmotic and ionic homeostasis (Vinocur and Altman 2005). Moreover, under heat stress, reactive

Submitted 13 March 2017, last revision 5 October 2017, accepted 6 November 2017.

| Abbreviations: APX - ascorbate peroxidase; AsA - ascorbate; CAT - catalase; DHAR - dehydroascorbate reductase; FA - ferulic acid; GPX - guaiacol peroxidase; GR - glutathione reductase; GSH-Px - glutathione peroxidase; MDA - malondialdehyde; MDHAR monodehydroascorbate reductase; PCA - principal component analysis; ROS - reactive oxygen species; RWC - relative water content; SOD - superoxide dismutase.

Acknowledgments: This work was supported by the Special Fund for Forest Scientific Research in the Public Welfare (grant No. 201204402). ${ }^{\text {a }}$ - These authors contributed equally to this work.

* Corresponding author; fax: (+86) 538 8242217, e-mail: baijg@sdau.edu.cn 
oxygen species (ROS), such as superoxide anion $\left(\mathrm{O}_{2}{ }^{-*}\right)$ and hydrogen peroxide $\left(\mathrm{H}_{2} \mathrm{O}_{2}\right)$, are overproduced in plants (Almeselmani et al. 2006). The overproduced $\mathrm{O}_{2}{ }^{-}$ and $\mathrm{H}_{2} \mathrm{O}_{2}$ attack unsaturated fatty acids, thereby damaging cell membranes (Sairam et al. 2002). To eliminate the damage caused by ROS overproduction, plants have developed antioxidant enzymes including superoxide dismutase (SOD), catalase (CAT), guaiacol peroxidase (GPX), glutathione peroxidase (GSH-Px), ascorbate peroxidase (APX), monodehydroascorbate reductase (MDHAR), dehydroascorbate reductase (DHAR), and glutathione reductase (GR) (Cao et al. 2015).

Many phenolic compounds also show antioxidant activity that leads to ROS elimination (Sevgi et al. 2015). Endogenous phenolic compounds are accumulated during thermal stress in watermelon (Rivero et al. 2001). Pretreatment with cinnamic or $p$-hydroxybenzoic acids enhances heat tolerance of cucumber (Dai et al. 2012,

\section{Materials and methods}

Two-year-old seedlings of northern highbush blueberry (Vaccinium corymbosum L. cv. Bluecrop) were grown in $15-\mathrm{cm}$ diameter plastic pots, which were filled with sand. The seedlings were watered once per day with a nutrient solution ( $\mathrm{pH} 5.8)$, which consisted of $2 \mathrm{mM} \mathrm{Ca}\left(\mathrm{NO}_{3}\right)_{2}$, $3 \mathrm{mM} \mathrm{KNO}_{3}, 0.4 \mathrm{mM} \mathrm{K \textrm {K } _ { 2 } \mathrm { PO } _ { 4 } , 1 \mathrm { mM } \mathrm { MgSO }} 4,90 \mu \mathrm{M}$ Fe-EDTA-Na $2,45 \mu \mathrm{M} \mathrm{H}_{3} \mathrm{BO}_{3}, 10 \mu \mathrm{M} \mathrm{MnSO}, 0.7 \mu \mathrm{M}$ $\mathrm{ZnSO}_{4}, 0.4 \mu \mathrm{M} \mathrm{CuSO}_{4}$, and $0.07 \mu \mathrm{M}\left(\mathrm{NH}_{4}\right)_{2} \mathrm{MoO}_{4}$. The seedlings were cultivated at day/night temperatures of $25 / 20{ }^{\circ} \mathrm{C}$, a relative humidity of $75 \%$, a $12-\mathrm{h}$ photoperiod, and an irradiance of $600 \mu \mathrm{mol} \mathrm{m} \mathrm{m}^{-2} \mathrm{~s}^{-1}$ until they were $50 \mathrm{~cm}$ high (Kim et al. 2011). Then, 48 blueberry seedlings, 8 plants per group, were used to investigate the optimal concentration of FA that mitigated heat stress most efficiently. They were watered separately for $1 \mathrm{~d}$ with a nutrient solution containing different concentrations $(0,0.3,0.4,0.5,0.6$, and $0.7 \mathrm{mM})$ of FA. Subsequently, the seedlings were exposed to heat at $39 / 30{ }^{\circ} \mathrm{C}$ for $3 \mathrm{~d}$. Based on the results of these preliminary experiments, 56 blueberry seedlings were divided into 7 groups ( 8 plants each group). The leaves of one group were harvested. Meanwhile, three groups of seedlings were watered with a nutrient solution that was supplemented with an optimal concentration $(0.6 \mathrm{mM})$ of FA, and another three groups were watered with the nutrient solution only. After one day, the leaves of one group of FA-pretreated and one group of FA-untreated seedlings were harvested separately. Sand for planting the remaining seedlings was rinsed 15 times with water and 3 times with the nutrient solution. Then, two groups of FA-pretreated blueberry were exposed separately to normal $\left(25 / 20{ }^{\circ} \mathrm{C}\right)$ and elevated $\left(39 / 30{ }^{\circ} \mathrm{C}\right)$ temperatures for $3 \mathrm{~d}$ and named as "FA" and "FA+heat", respectively. Two groups of FA-untreated seedlings were also
Zhang et al. 2012). Exogenous ferulic acid (FA) is protective against heat stress in rats (He et al. 2016). However, pretreatment with FA has not been reported to mitigate heat stress in plants. Pretreatment with FA regulates antioxidant enzyme activities and alleviates dehydration stress in cucumber (Li et al. 2013); therefore, we hypothesize that pretreatment with FA might enhance plants ability to resist heat stress by activating antioxidant enzymes.

In this study, northern highbush blueberry seedlings were pretreated with FA and then subjected to heat stress. Thereafter, the transcriptions of antioxidant enzyme genes were analyzed. Our aims were to verify whether exogenous FA alleviates heat stress in plants and whether such stress alleviation is associated with the regulation of antioxidant enzymes. Moreover, proline and soluble sugars play roles in mitigating heat stress (Huang et al. 2015); therefore, their content was also determined.

subjected to the two temperature regimes indicated above for $3 \mathrm{~d}$, and named as "control" and "heat", respectively. The leaves of the four groups of blueberry were collected. Three biological replicates were performed for each treatment.

Endogenous FA content was measured at $290 \mathrm{~nm}$ with an Agilent 1200 rapid resolution liquid chromatography system (Agilent Technologies, Waldbronn, Germany) following the procedures of Wang et al. (2004) modified by Wan et al. (2015). Relative water content (RWC) in leaves was determined according to Barrs and Weatherley (1962) using 1-cm diameter leaf discs, which were saturated in water for $5 \mathrm{~h}$. Osmotic potential was measured by using liquid nitrogen-frozen leaves according to Bajji et al. (2001). Malondialdehyde (MDA) content was measured at 450, 532, and $600 \mathrm{~nm}$ according to procedures described by Dhindsa et al. (1981) and modified by $\mathrm{Xu}$ et al. (2008). Rate of $\mathrm{O}_{2}{ }^{--}$formation was measured by using the method of hydroxylamine oxidation following the procedures of Wan et al. (2015). Content of $\mathrm{H}_{2} \mathrm{O}_{2}$ was measured by utilizing $o$-dianisidine and peroxidase according to Bernt and Bergmeyer (1974) as modified by Li et al. (2013).

To estimate iron superoxide dismutase ( $F e-S O D)$, chloroplast copper/zinc superoxide dismutase (Chl $\mathrm{Cu} / \mathrm{Zn}$-SOD), cytoplasmic copper/zinc superoxide dismutase (Cyt Cu/Zn-SOD), CAT, GPX, GSH-Px, APX, $D H A R, M D H A R$, and $G R$ gene expressions, total RNA was extracted from leaves using the method of Yu et al. (2016) and then reverse-transcribed to cDNA using a Quantscript RT kit (Cwbio, Beijing, China). Real-time quantitative PCR was performed in a $20-\mathrm{mm}^{3}$ reaction system containing $10 \mathrm{~mm}^{3}$ of $2 \times$ ultra $S Y B R$ mixture with Rox (Cwbio), $2 \mathrm{~mm}^{3}$ of template cDNA, and $0.3 \mathrm{~mm}^{3}$ of 
each 5 pmol forward and reverse primers (Table 1 Suppl.). Parameters of PCR included an initial denaturation step at $95{ }^{\circ} \mathrm{C}$ for $10 \mathrm{~min}$ followed by 39 cycles at $95{ }^{\circ} \mathrm{C}$ for $15 \mathrm{~s}$ and at $55^{\circ} \mathrm{C}$ for $1 \mathrm{~min}$. Gene expressions were normalized against corresponding $18 \mathrm{~S}$ rRNA expression and calculated by using the $2^{-\Delta \Delta \mathrm{Ct}}$ comparative threshold (CT) method (Rimando et al. 2012).

Activity of SOD was determined at $560 \mathrm{~nm}$ according to the method of Hwang et al. (1999), and 1 unit of activity is defined as the amount of SOD that inhibits $50 \%$ of nitroblue tetrazolium reduction. Activity of GSH-Px was measured at $412 \mathrm{~nm}$ using $\mathrm{H}_{2} \mathrm{O}_{2}$ as a substrate (Xue et al. 2001). Ascorbate (AsA) content was measured by utilizing 2,6-dichlorophenol (Klein and Perry 1982). Reduced glutathione (GSH) content was determined at $412 \mathrm{~nm}$ by using 5,5'-dithiobis-

\section{Results}

When different concentrations $(0,0.3,0.4,0.5,0.6$, and $0.7 \mathrm{mM}$ ) of FA were applied to the blueberry seedlings before the plants were exposed to heat stress, $0.6 \mathrm{mM}$ FA decreased the content of MDA, $\mathrm{O}_{2}{ }^{\circ}$, and $\mathrm{H}_{2} \mathrm{O}_{2}$ in leaves to their lowest values (Fig. 1). Compared with the other concentrations $(0,0.3,0.4,0.5$ and $0.7 \mathrm{mM})$ of FA under heat stress, $0.6 \mathrm{mM}$ FA reduced MDA content by 22.99 , $23.98,26.78,28.53$, and $10.94 \%$, respectively; decreased $\mathrm{O}_{2}{ }^{--}$production rate by $57.57,52.97,46.24,58.36$, and $49.61 \%$, respectively; and reduced $\mathrm{H}_{2} \mathrm{O}_{2}$ content by (2-nitrobenzoic) acid according to Guri (1983). Protein content in each enzyme extract was measured at $595 \mathrm{~nm}$ (Bradford 1976).

Proline content was measured at $520 \mathrm{~nm}$ following the procedure of Bates et al. (2013). Soluble sugar content was determined using anthrone (Yemm and Willis 1954).

Data were expressed as means \pm standard errors (SEs) from three biological replicates. Differences were analyzed by one-way analysis of variance ( $A N O V A)$ and the least significant difference (LSD) test, and multivariate statistical analysis was carried out with principal components analysis (PCA). All statistical analyses were carried out using SPSS 22.0 for Windows (IBM Corp., Armonk, NY, USA). $P$-values of $<0.05$ were considered as significant.

$30.69,33.88,35.37,36.19$, and $29.47 \%$, respectively.

When the blueberry seedlings were pretreated with $0,0.3,0.4,0.5,0.6$, and $0.7 \mathrm{mM} F A$ and then subjected to heat, $0.6 \mathrm{mM}$ FA led to the highest activities of SOD and GSH-Px (Fig. 1). Compared with 0, 0.3, 0.4, 0.5, and $0.7 \mathrm{mM}$ in heat-stressed leaves, pretreatment with $0.6 \mathrm{mM}$ FA increased SOD activity by $28.61,15.57$, $14.03,8.12$, and $5.17 \%$, respectively; and enhanced GSH-Px activity by $88.68,86.55,64.01,69.21$, and $38.20 \%$, respectively.

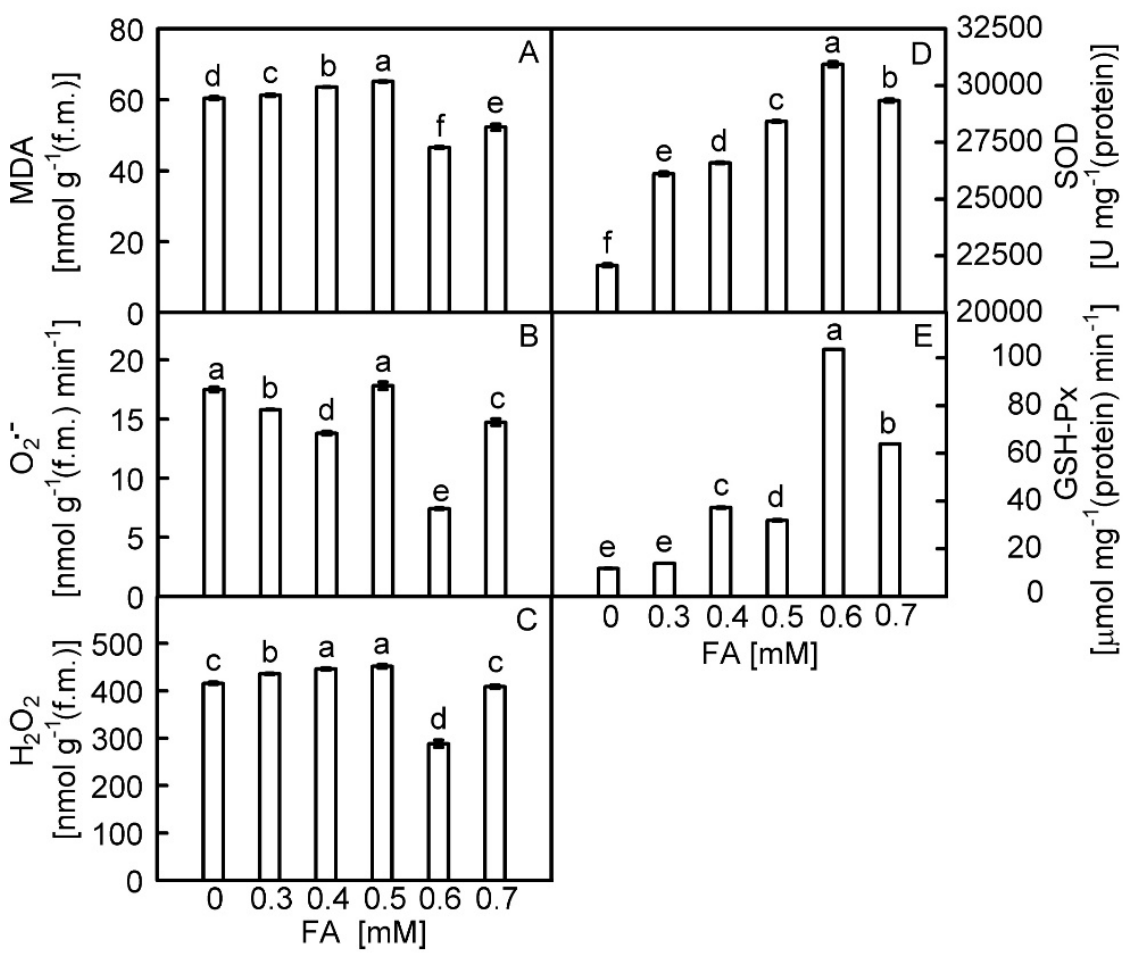

Fig. 1. Effects of pretreatment with different concentrations of ferulic acid (FA) on MDA content $(A), \mathrm{O}_{2}{ }^{--}$production rate $(B)$, content of $\mathrm{H}_{2} \mathrm{O}_{2}(C)$, and activities of SOD $(D)$ and GSH-Px $(E)$ in blueberry leaves under heat stress $\left(39 / 30^{\circ} \mathrm{C}\right.$ for $\left.3 \mathrm{~d}\right)$. Means \pm SEs, $n=3$. Values with the different letters are significantly different at $P<0.05$ according to the LSD test. 
In comparison to FA-untreated blueberries, RWC in leaves was not changed in the FA-treated seedlings for $1 \mathrm{~d}$, whereas osmotic potential of leaves increased by $9.12 \%$ (Fig. 2). After $4 \mathrm{~d}$, RWC in leaves of the FA-treated seedlings did not change, and osmotic potential in leaves was enhanced by $7.7 \%$ in comparison to untreated ones. In the heat treatment group, RWC and osmotic potential in leaves were reduced by 20.29 and $3.29 \%$, respectively, compared with the control group. When we compared the FA+heat treatment group with the heat treatment group, RWC and osmotic potential in leaves increased by 18.13 and $3.49 \%$, respectively.

Compared to the FA-untreated blueberries, content of endogenous FA in leaves increased by $2.98 \%$ in the FA-pretreated seedlings after $1 \mathrm{~d}$ (Fig. 2). After $4 \mathrm{~d}$, endogenous FA content in leaves of the FA-pretreated seedlings and the heat treated groups increased by 1.28 and $1.92 \%$, respectively, compared with the control group. In the FA+heat treatment group compared with the heat treatment group, endogenous FA content in leaves was enhanced by $0.63 \%$.

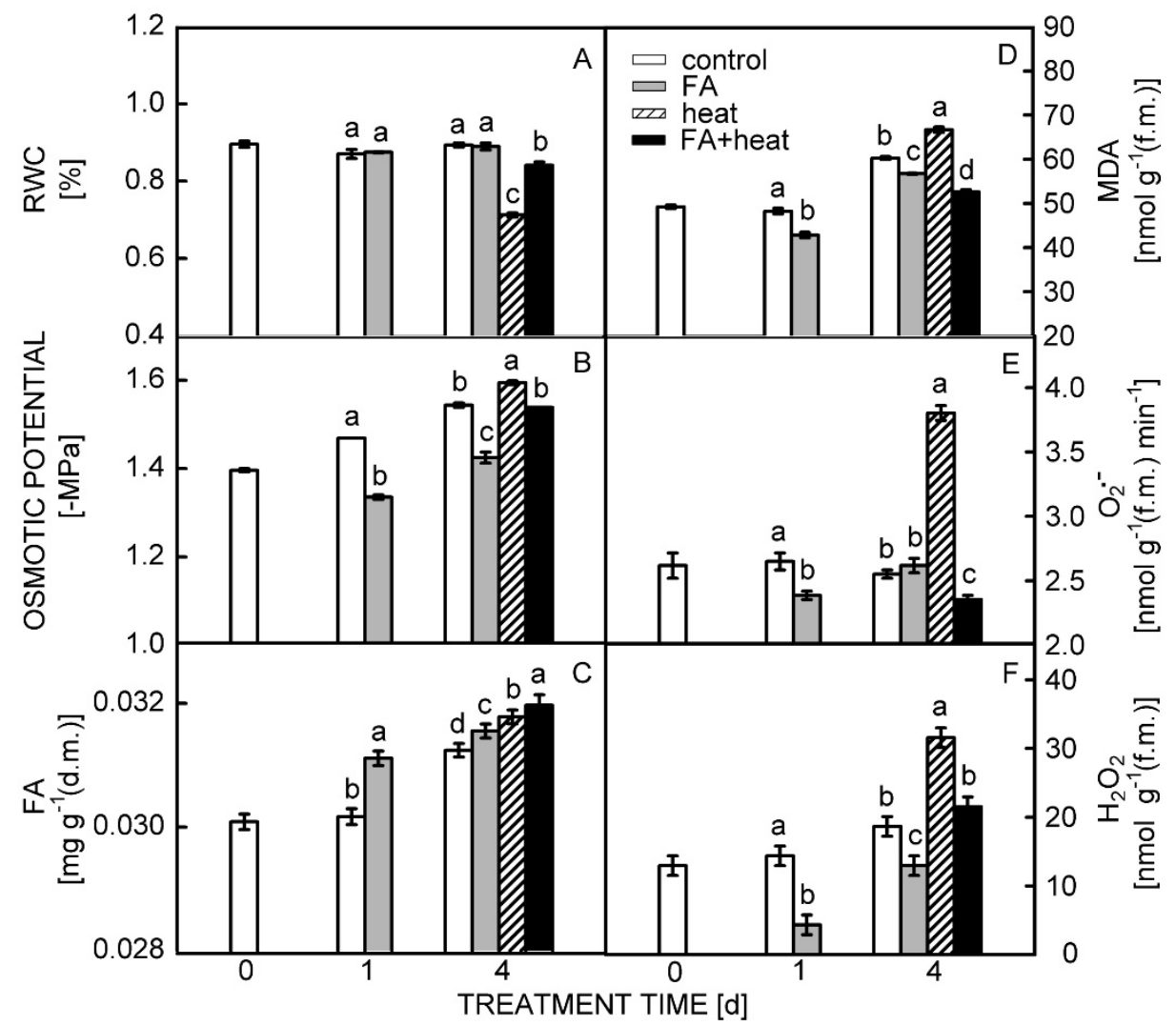

Fig. 2. Effects of FA pretreatment and heat stress on relative water content (RWC) $(A)$, osmotic potential $(B)$, endogenous FA content $(C)$, MDA content $(D), \mathrm{O}_{2}{ }^{-}$production rate $(E)$, and $\mathrm{H}_{2} \mathrm{O}_{2}$ content $(F)$ in blueberry leaves. Control - treated at $25 / 20{ }^{\circ} \mathrm{C}$; FA - pretreated with $0.6 \mathrm{mM}$ FA and treated at $25 / 20{ }^{\circ} \mathrm{C}$; heat - treated at $39 / 30{ }^{\circ} \mathrm{C}$; FAtheat - pretreated with $0.6 \mathrm{mM}$ FA and treated at $39 / 30^{\circ} \mathrm{C}$. Means \pm SEs, $n=3$. Values with different letters are significantly different at $P<0.05$ according to the LSD test.

Content of MDA and $\mathrm{H}_{2} \mathrm{O}_{2}$ and $\mathrm{O}_{2}^{--}$production rate in leaves were decreased by $11.12,9.94$, and $69.87 \%$, respectively, in the FA-pretreated seedlings for $1 \mathrm{~d}$ in comparison with the FA-untreated blueberries (Fig. 2). After $4 \mathrm{~d}$, comparing the FA pretreatment group with the control group, content of MDA and $\mathrm{H}_{2} \mathrm{O}_{2}$ in leaves decreased by 5.87 and $30.72 \%$, respectively, and $\mathrm{O}_{2}{ }^{-}$ production showed no change. Comparison of the heat treatment group with the control group reveals content of MDA, production rate of $\mathrm{O}_{2}{ }^{--}$, and content of $\mathrm{H}_{2} \mathrm{O}_{2}$ increased by $10.63,49.03$, and $69.12 \%$, respectively. Comparing the FA+heat treatment group with the heat treatment group, content of $\mathrm{MDA}, \mathrm{O}_{2}{ }^{--}$production, and
$\mathrm{H}_{2} \mathrm{O}_{2}$ content decreased by $21.12,38.10$, and $31.79 \%$, respectively.

Compared with the FA-untreated blueberries, transcriptions of $\mathrm{Fe}-\mathrm{SOD}, \mathrm{Cyt} \mathrm{Cu} / \mathrm{Zn}-\mathrm{SOD}, \mathrm{GPX}, \mathrm{GSH}$ $P x, M D H A R$, and $G R$ in leaves were elevated by 100.8 , $40.72,103.48,24.36,22.37$, and $89.52 \%$, respectively, in the FA-pretreated seedlings for $1 \mathrm{~d}$. At the same time, transcription of $\mathrm{Chl} \mathrm{Cu} / \mathrm{Zn}-\mathrm{SOD}$ was reduced by $13.72 \%$, and transcription of $C A T, A P X$, and DHAR did not change (Fig. 3). After $4 \mathrm{~d}$, transcriptions of $\mathrm{Fe}-\mathrm{SOD}, \mathrm{Cyt} \mathrm{Cu} / \mathrm{Zn}$ SOD, Chl Cu/Zn-SOD, CAT, GPX, GSH-Px, APX, MDHAR, DHAR, and GR increased by $120.29,124.63$, $182.54,101.16,91.86,118.64,183.71,88.63,144.34$, and 


\section{Z.-Y. CHENG et al.}

$151.55 \%$, respectively, in the FA pretreatment group compared with the control group. When the heat treatment group was compared with the control group, transcriptions of $C y t \mathrm{Cu} / \mathrm{Zn}-\mathrm{SOD}, \mathrm{Chl} \mathrm{Cu} / \mathrm{Zn}-\mathrm{SOD}, \mathrm{CAT}$, $G P X, G S H-P x, A P X, M D H A R, D H A R$, and GR increased by $90.74,266.63,122.77,59.05,24.41,319.38,80.78$, 172.08 , and $139.35 \%$, respectively; transcription of
Fe-SOD decreased by $15.85 \%$. Comparing the FA+heat treatment group with the heat treatment group, transcriptions of $\mathrm{Fe}-\mathrm{SOD}, \mathrm{Cyt} \mathrm{Cu} / \mathrm{Zn}-\mathrm{SOD}, \mathrm{Chl} \mathrm{Cu} / \mathrm{Zn}$ SOD, CAT, GPX, GSH-Px, APX, MDHAR, DHAR, and $G R$ in leaves were increased by $86.85,65.34,50.86$, $42.77,49.39,46.53,56.98,51.28,47.73$, and $58.79 \%$, respectively.

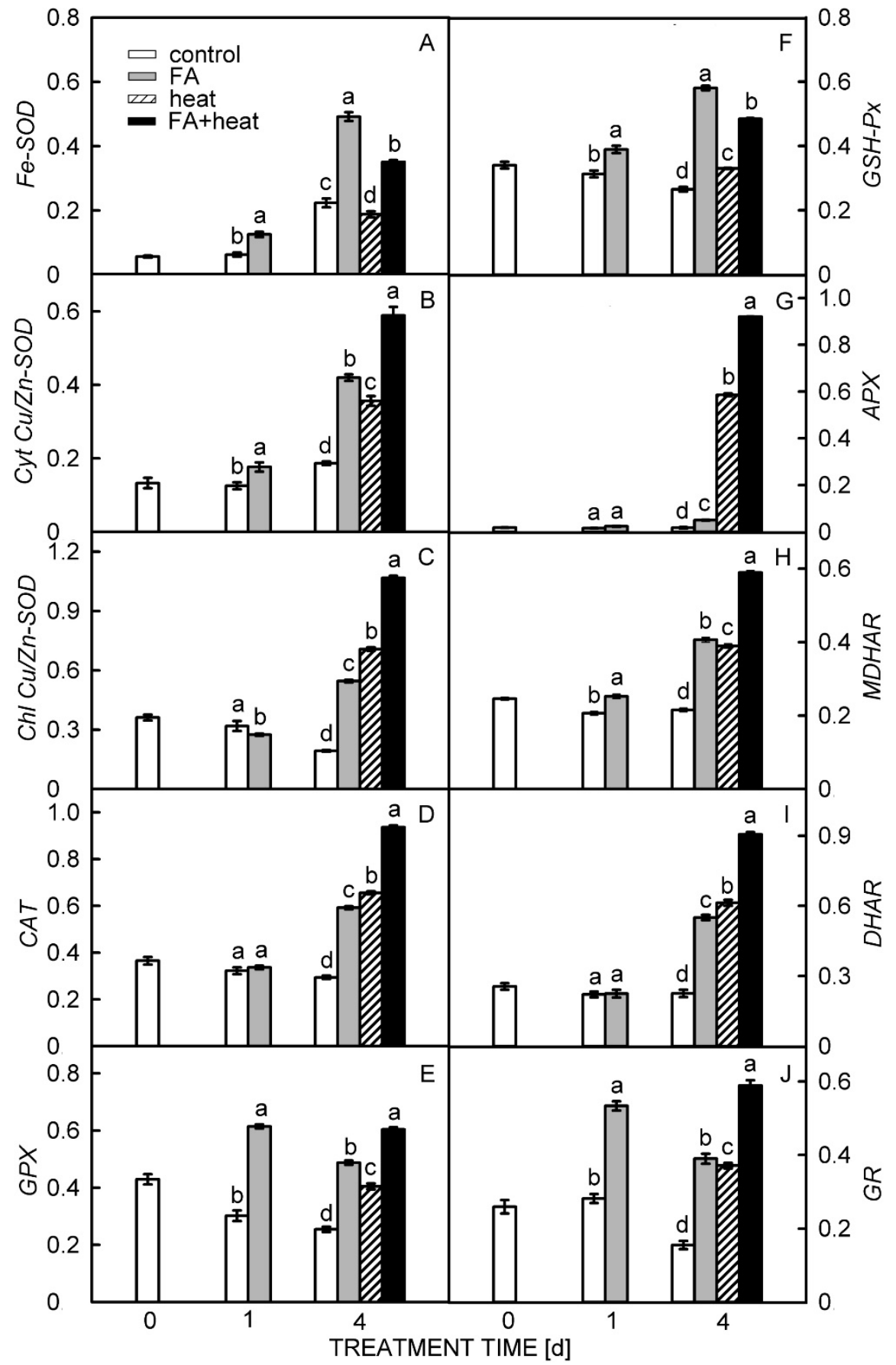

Fig. 3. Effects of FA pretreatment and heat stress on transcriptions of $\mathrm{Fe}-\mathrm{SOD}(\mathrm{A}), \mathrm{Cyt} \mathrm{Cu} / \mathrm{Zn}$-SOD (B), Chl Cu/Zn-SOD (C),CAT $(D), G P X(E), G S H-P x(F), A P X(G), \operatorname{MDHAR}(H), D H A R(I)$, and $G R(J)$ in blueberry leaves. Means \pm SEs, $n=3$. Values with different letters are significantly different at $P<0.05$ according to the LSD test. For more detail see Fig. 2. 
Compared with the FA-untreated blueberries, SOD activity in leaves increased by $24.70 \%$ in the FA-pretreated seedlings for $1 \mathrm{~d}$, and activity of GSH-Px decreased by $29.46 \%$ (Fig. 4). Compared to the control group, activities of SOD in the FA pretreatment for $4 \mathrm{~d}$ and heat treatment groups increased by 36.23 and $36.76 \%$, respectively; activity of GSH-Px was enhanced by $5.37 \%$ in the FA pretreatment group and reduced by $8.66 \%$ in the heat treatment group. In the FA+heat treatment group compared to the heat treatment group, activities of SOD and GSH-Px in leaves were elevated by 45.89 and $20.00 \%$, respectively.

Content of AsA decreased by $17.63 \%$ in the FA-pretreated blueberries for $1 \mathrm{~d}$ compared with the FA-untreated seedlings, but content of GSH was elevated by $6.45 \%$ (Fig. 4). After $4 \mathrm{~d}$, AsA and GSH content increased by 2.49 and $13.22 \%$ in the FA pretreated group and by 13.66 and $10.34 \%$, respectively, in the heat treatment group as compared with the control group. Compared with the heat treatment group, content of GSH and AsA in leaves of the FA+heat treatment group were enhanced by 3.35 and $9.02 \%$, respectively.

Content of proline and soluble sugars in leaves of the FA-pretreated blueberries for $1 \mathrm{~d}$ were enhanced by 12.93 and $1.28 \%$, respectively, compared with the FA-untreated seedlings (Fig. 4). After $4 \mathrm{~d}$, content of proline and soluble sugars in leaves increased by 7.69 and $1.75 \%$, respectively, in the FA pretreatment group compared with the control group. When comparing the heat treatment group with the control group, proline content increased by $14.82 \%$ and soluble sugar content decreased by $0.38 \%$. In the FAtheat treatment group, content of proline and soluble sugars was enhanced by 9.55 and $1.35 \%$, respectively, compared with the heat treatment group.

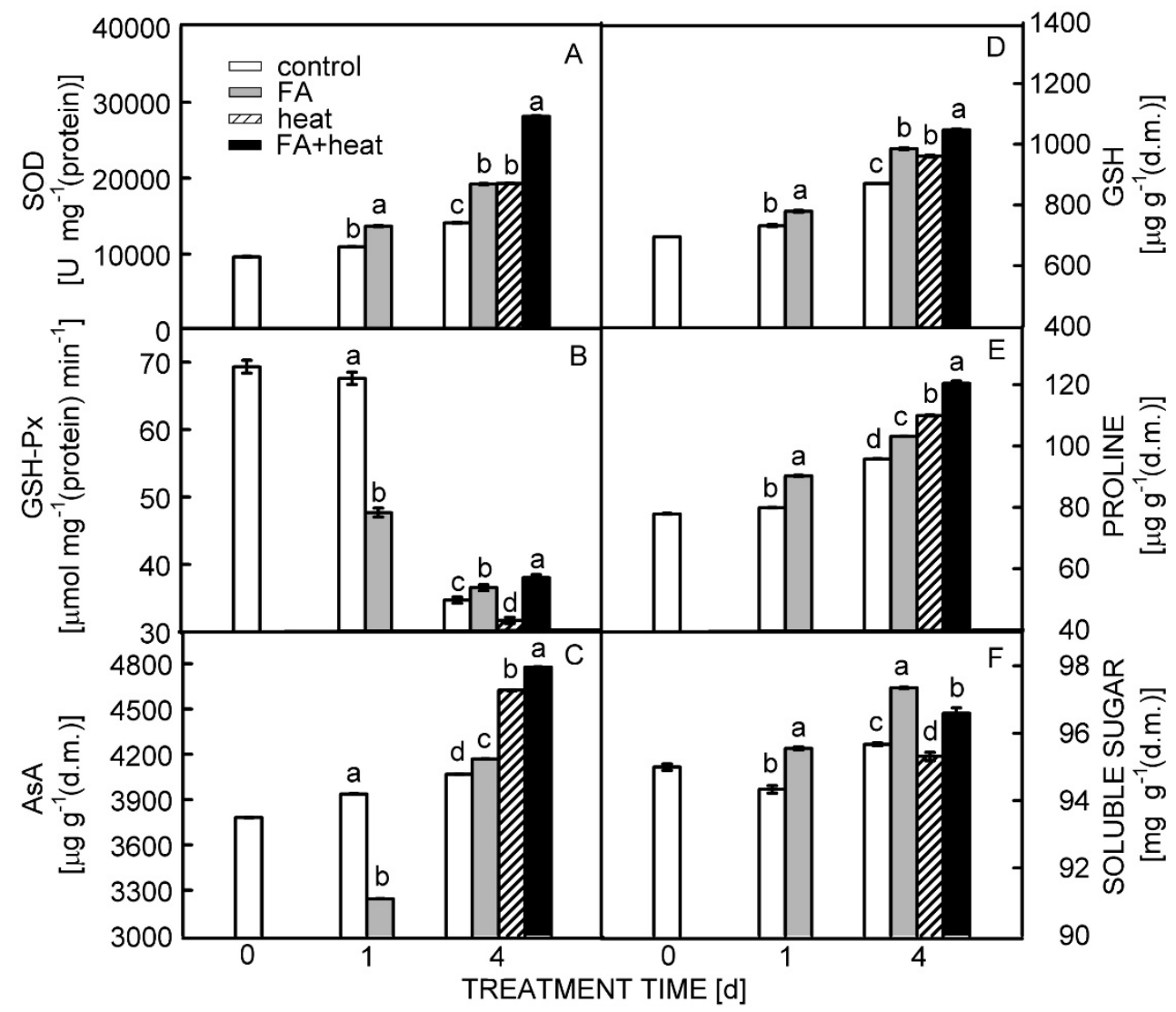

Fig. 4. Effects of FA pretreatment and heat stress on activities of SOD $(A)$ and GSH-Px $(B)$, content of AsA $(C)$, GSH $(D)$, proline $(E)$, and soluble sugars $(F)$ in blueberry leaves. Means \pm SEs, $n=3$. At each treatment time, values with different letters are significantly different at $P<0.05$ according to the LSD test. For more detail see Fig. 2.

As shown in the scree plot, three main components presented as the first three dots from the left were identified (Fig. 1 Suppl.). The first component (PC1) accounted for $60.92 \%$ of the variance, and the second one (PC2) accounted for $32.61 \%$. The first two components explained $93.53 \%$ of the total variation, and the third component was thus neglected. According to the loading plot, $\mathrm{PC} 1$ provided 13 dominant variables (transcriptions of GPX,Cyt Cu/Zn-SOD, GR, MDHAR, CAT, DHAR, APX, and Chl Cu/Zn-SOD; content of FA, GSH, AsA, and proline; and SOD activity) as positive values, which were inversely correlated with another 
dominant variable (MDA content). For PC2, six dominant variables (RWC, osmotic potential, content of soluble sugars, transcriptions of $\mathrm{Fe}-\mathrm{SOD}$ and $\mathrm{GSH}-\mathrm{Px}$, and GSH-Px activity) were positive values, having an inverse correlation with three other dominant variables (content of MDA and $\mathrm{H}_{2} \mathrm{O}_{2}$, and $\mathrm{O}_{2}{ }^{-}$production rate). Simultaneous analysis of the loading and score plots shows that the FA pretreatment group had a direct correlation with RWC, osmotic potential, content of soluble sugars, transcriptions of $\mathrm{Fe}-\mathrm{SOD}$ and $\mathrm{GSH}-\mathrm{Px}$, and GSH-Px activity. The FAtheat treatment group correlated with transcriptions of $G P X, C y t C u / Z n-S O D$, GR, MDHAR, CAT, DHAR, APX, and Chl Cu/Zn-SOD; content of FA, GSH, AsA, and proline; and SOD activity. Meanwhile, the heat treatment correlated with content of MDA and $\mathrm{H}_{2} \mathrm{O}_{2}$, and $\mathrm{O}_{2}{ }^{--}$production rate.

\section{Discussion}

As an indicator of stress damage, MDA accumulates under heat (Huang et al. 2015). Meanwhile, RWC (Jiang and Huang 2001) and osmotic potential in leaves (Pang et al. 2013) decrease. In the present study, under day/ night temperatures elevated from $25 / 20{ }^{\circ} \mathrm{C}$ to $39 / 30{ }^{\circ} \mathrm{C}$, MDA content in leaves increased, and RWC and osmotic potential decreased suggesting that a high temperature had a deleterious effect on water status and caused stress in the blueberry seedlings. Pretreatment with cinnamic acid increases RWC in leaves, decreases MDA content, and alleviates heat stress (Dai et al. 2012). Salicylic acid treatment enhances osmotic potential and mitigates heat stress (Khan et al. 2013). In the present study, when the blueberries were pretreated with $0.6 \mathrm{mM}$ FA and then exposed to heat stress, MDA content decreased, and RWC and osmotic potential in leaves increased indicating that FA improved water status under heat and alleviated heat stress in the blueberries.

In this study, heat enhanced content of endogenous FA. Similarly, Cheng et al. (2006) reported that phenolic acid content increases in heat-stressed wheat. In our heatstressed blueberries, endogenous FA content was further elevated by FA pretreatment. Similarly, pretreatment of cucumber with cinnamic acid increases its endogenous content under heat stress (Dai et al. 2012). The enhanced FA content in the present experiment coincided with the decreased content of MDA in the FA-pretreated heatstressed blueberries. Moreover, PCA results show that FA content is inversely correlated with MDA content. These results indicate that FA pretreatment elevated endogenous FA content thus mitigating following heat stress.

Under heat stress, an increased MDA content can be caused by ROS accumulation (Chen et al. 2012). In the present study, the heat-stressed blueberries had an increased $\mathrm{O}_{2}^{-}$production rate and $\mathrm{H}_{2} \mathrm{O}_{2}$ content, which correlated with enhanced MDA content. Pretreatment with $p$-hydroxybenzoic acid causes a decrease in content of $\mathrm{O}_{2}{ }^{--}$and $\mathrm{H}_{2} \mathrm{O}_{2}$ under high temperature (Zhang et al. 2012). In the present study, the combination of FA pretreatment and heat reduced $\mathrm{O}_{2}{ }^{--}$and $\mathrm{H}_{2} \mathrm{O}_{2}$ content in leaves in comparison to heat treatment alone. This is consistent with the decreased amount of MDA and the enhanced RWC in FA-pretreated and heat-stressed leaves suggesting that pretreatment with FA mitigated heat stress in the blueberries by decreasing ROS accumulation.

The $\mathrm{O}_{2}{ }^{--}$is dismutated by SOD (Choudhury et al. 2013). In heat-stressed bluberry leaves, transcription of $\mathrm{Fe}-\mathrm{SOD}$ decreased, but transcriptions of $\mathrm{Chl} \mathrm{Cu} / \mathrm{Zn}-\mathrm{SOD}$ and $\mathrm{Cyt} \mathrm{Cu} / \mathrm{Zn}$-SOD were enhanced; therefore, overall SOD activity increased. However, the elevated SOD activity was not consistent with the increased $\mathrm{O}_{2}{ }^{-}$ production rate under the heat treatment. The reason may be that the generation of $\mathrm{O}_{2}{ }^{--}$exceeded the ability of SOD to dismutate it. By contrast, when the blueberries were pretreated with FA for $1 \mathrm{~d}$, transcriptions of $\mathrm{Fe}-S O D$ and $C y t \mathrm{Cu} / \mathrm{Zn}-\mathrm{SOD}$ and activity of SOD increased. Similarly, application of FA elevates SOD activity in cucumber seedlings (Li et al. 2013). Caffeic acid pretreatment also elevates SOD activity thereby decreases $\mathrm{O}_{2}{ }^{--}$content and alleviates chilling stress (Wan et al. 2015). When the FA-pretreated blueberries were exposed to heat in the current study, transcriptions of $\mathrm{Fe}-\mathrm{SOD}, \mathrm{Cyt} \mathrm{Cu} / \mathrm{Zn}-\mathrm{SOD}$, and $\mathrm{Chl} C \mathrm{Cu} / \mathrm{Zn}-\mathrm{SOD}$, and activity of SOD in leaves were higher than under heat treatment alone. The higher

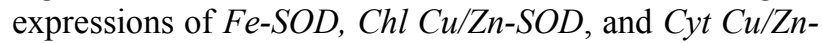
$S O D$ and the elevated activity of SOD were in accordance with the reduced $\mathrm{O}_{2}{ }^{--}$production rate and MDA content in the FA-pretreated and heat-stressed leaves. These results suggest that exogenous FA regulated $\mathrm{O}_{2}{ }^{--}$content via increased SOD activity and so mitigated heat stress.

Content of $\mathrm{H}_{2} \mathrm{O}_{2}$ can be regulated by CAT, GPX, GSH-Px, or APX (Wan et al. 2015). As a response to heat stress, transcriptions of $C A T, G P X, G S H-P x$, and $A P X$ in blueberry leaves increased. Similarly, a previous study has noted that heat elevates activities of CAT, GPX, GSH-Px, and APX in cucumber (Dai et al. 2012). In our study, transcriptions of GPX and GSH-Px increased in the FA-pretreated seedlings for $1 \mathrm{~d}$. This is similar to the effect of caffeic acid treatment in enhancing activities of GPX and GSH-Px in cucumber (Wan et al. 2015). After $4 \mathrm{~d}$, when FA has been rinsing off for $3 \mathrm{~d}$, transcriptions of GPX and GSH-Px in the FA pretreatment group remains higher than in the control indicating that the effects of FA persists. In the current study, transcriptions of $C A T$ and $A P X$ showed no change in the FA-pretreated blueberries after $1 \mathrm{~d}$ but increased after $4 \mathrm{~d}$. The reason may be that there were gene interactions for antioxidant enzymes in plants (Yun et al. 
1998), and the higher transcriptions of $G P X$ and $G S H-P x$ in the FA pretreatment group induced expressions of $C A T$ and $A P X$. Pretreatment with paraquat enhances activities of CAT, GPX, GSH-Px, and APX in cucumber thereby reduces $\mathrm{H}_{2} \mathrm{O}_{2}$ content and mitigates heat stress (Gao et al. 2011). In the FA-pretreated and heat-stressed blueberry seedlings, transcriptions of $C A T$, $G P X, G S H-P x$, and $A P X$ were higher than in the seedlings treated with heat alone, which is in agreement with the elevated activity of GSH-Px and the lower content of $\mathrm{H}_{2} \mathrm{O}_{2}$ and MDA. Moreover, the PCA results reveal that transcription of GSH-Px and activity of GSH-Px were inversely correlated with $\mathrm{H}_{2} \mathrm{O}_{2}$ content. These results indicate that exogenous FA decreased $\mathrm{H}_{2} \mathrm{O}_{2}$ content and alleviated heat stress via increased activities of CAT, GPX, and APX, and especially via GSH-Px activity.

In the ascorbate-glutathione cycle, GR regenerates GSH, and GSH-dependent DHAR and/or NADHdependent MDHAR reproduces AsA. The resulting GSH and AsA not only act as substrates for APX action but also lead to ROS detoxification attributed to a reduction in MDA (Lin et al. 2011). Under heat, transcriptions of $G R, D H A R$, and MDHAR were enhanced in the present study, and this may represent a response to stress conditions. Similarly, transcriptions of $G R, D H A R$, and $M D H A R$ increase by a low temperature (Baek and Skinner 2003). p-Hydroxybenzoic acid regulates GR, DHAR, and MDHAR activities and mitigates heat stress in cucumber (Zhang et al. 2012). In the FAtheat treatment, in comparison with the heat treatment alone, transcriptions of $G R, D H A R$, and MDHAR were enhanced, which was supported by the increased content of GSH and AsA and coincided with the reduced content of MDA. These results suggest that GR, DHAR, and MDHAR played a role in FA pretreatment-associated

\section{References}

Almeselmani, M., Deshmukh, P.S., Sairam, R.K., Kushwaha, S.R., Singh, T.P.: Protective role of antioxidant enzymes under high temperature stress. - Plant Sci. 171: 382-388, 2006.

Baek, K.H., Skinner, D.Z.: Alteration of antioxidant enzyme gene expression during cold acclimation of near-isogenic wheat lines. - Plant Sci. 165: 1221-1227, 2003.

Bajji, M., Lutts, S., Kinet, J.M.: Water deficit effects on solute contribution to osmotic adjustment as a function of leaf ageing in three durum wheat (Triticum durum Desf.) cultivars performing differently in arid conditions. - Plant Sci. 160: 669-681, 2001.

Barrs, H.D., Weatherley, P.E.: A re-examination of the relative turgidity technique for estimating water deficit in leaves. Aust. J. biol. Sci. 15: 413-428, 1962.

Bates, L.S., Waldren, R.P., Teare, I.D.: Rapid determination of free proline for water-stress studies. - Plant Soil 39: 205207, 2013.

Bernt, E., Bergmeyer, H.U.: Inorganic peroxides. - In: Bergmeyer, H.U. (ed.): Methods of Enzymatic Analysis. Pp. mitigation of heat stress.

Under heat stress, proline content increased and soluble sugar content decreased in blueberry leaves. Similarly, heat enhances proline content in lettuce seedlings (Han et al. 2013) and reduces soluble sugar content in eggplant seedlings (Jia and Chen 2005). In the FA-pretreated and heat-stressed blueberries, content of proline and soluble sugars were higher than in the seedlings treated with heat only. These results suggest that proline and soluble sugars were related to the heat mitigation induced by exogenous FA. Similarly, glucose pretreatment elevates proline and soluble sugar content and thus improves heat tolerance of cucumber (Huang et al. 2015).

In conclusion, the heat treatment $\left(39 / 30^{\circ} \mathrm{C}\right)$ increased MDA content and caused stress in the blueberries. One day after pretreatment with $0.6 \mathrm{mM}$ FA, elevated transcriptions of $\mathrm{Fe}-\mathrm{SOD}, \mathrm{Cyt} \mathrm{Cu} / \mathrm{Zn}-\mathrm{SOD}, \mathrm{GPX}, \mathrm{GSH}$ $P x, M D H A R$, and $G R$ and increased content of proline and soluble sugars in leaves were detected. When the FA-pretreated blueberries were exposed to the heat stress, transcriptions of $\mathrm{Fe}-\mathrm{SOD}, \mathrm{Cyt} \mathrm{Cu} / \mathrm{Zn}-\mathrm{SOD}, \mathrm{Chl} \mathrm{Cu/Zn-}$ SOD, CAT, GPX, GSH-Px, APX, DHAR, MDHAR, and $G R$ increased compared with the heat treatment alone, and also content of proline and soluble sugars were further enhanced. Compared to the heat treatment alone, the combination of FA pretreatment and heat also increased content of endogenous FA, elevated activities of SOD and GSH-Px, enhanced content of AsA and $\mathrm{GSH}$, decreased content of $\mathrm{O}_{2}{ }^{--}, \mathrm{H}_{2} \mathrm{O}_{2}$, and MDA, and increased RWC and osmotic potential in the blueberry leaves. We propose that exogenous FA mitigates heat stress by enhancing content of endogenous FA, increasing content of proline and soluble sugars, and inducing expression of antioxidant enzyme genes.
2246-2248. Academic Press, New York 1974.

Bradford, M.M.: A rapid and sensitive method for the quantitation of microgram quantities of protein utilizing the principle of protein-dye binding. - Anal. Biochem. 72: 248254, 1976.

Cao, Y.Y., Yang, M.T., Chen, S.Y., Zhou, Z.Q., Li, X., Wang, X.J., Bai, J.G.: Exogenous sucrose influences antioxidant enzyme activities and reduces lipid peroxidation in waterstressed cucumber leaves. - Biol. Plant. 59: 147-153, 2015.

Chen, W., Cen, W., Chen, L., Di, L., Li, Y., Guo, W.: Differential sensitivity of four highbush blueberry (Vaccinium corymbosum L.) cultivars to heat stress. - Pak. J. Bot. 44: 853-860, 2012.

Cheng, Z.H., Su, L., Moore, J., Zhou, K.Q., Luther, M., Yin, J.J., Yu, L.L.: Effects of postharvest treatment and heat stress on availability of wheat antioxidants. - J. Agr. Food Chem. 54: 5623-5629, 2006.

Choudhury, S., Panda, P., Sahoo, L., Panda, S.K.: Reactive oxygen species signaling in plants under abiotic stress. Plant Signal Behav. 8: e23681, 2013. 
Dai, A.H., Nie, Y.X., Yu, B., Li, Q., Lu, L.Y., Bai, J.G.: Cinnamic acid pretreatment enhances heat tolerance of cucumber leaves through modulating antioxidant enzyme activity. - Environ. exp. Bot. 79: 1-10, 2012.

Dhindsa, R.S., Plumb-Dhindsa, P., Thorpe, T.A.: Leaf senescence: correlated with increased levels of membrane permeability and lipid peroxidation and decreased levels of superoxide dismutase and catalase. - J. exp. Bot. 32: 93-101, 1981.

Elstner, E.F., Heupel, A.: Inhibition of nitrite formation from hydroxylammonium chloride: a simple assay for superoxide dismutase. - Anal. Biochem. 70: 616-620, 1976.

Gao, Y., Guo, Y.K., Dai, A.H., Sun, W.J., Bai, J.G.: Paraquat pretreatment alters antioxidant enzyme activity and protects chloroplast ultrastructure in heat-stressed cucumber leaves. Biol. Plant. 55: 788-792, 2011.

Guri, A.: Variation in glutathione and ascorbic acid content among selected cultivars of Phaseolus vulgaris prior to and after exposure to ozone. - Can. J. Plant Sci. 63: 733-737, 1983.

Han, Y., Fan, S., Zhang, Q., Wang, Y.: Effect of heat stress on the MDA, proline and soluble sugar content in leaf lettuce seedlings. - Agr. Sci. 4: 112-115, 2013.

He, S., Liu, F., Xu, L., Yin, P., Li, D., Mei, C., Jiang, L., Ma, Y., Xu, J.: Protective effects of ferulic acid against heat stress-induced intestinal epithelial barrier dysfunction in vitro and in vivo. - PLoS ONE 11: e0145236, 2016.

Huang, B., $\mathrm{Xu}, \mathrm{C}$. : Identification and characterization of proteins associated with plant tolerance to heat stress. - J. Integr. Plant Biol. 50: 1230-1237, 2008.

Huang, Y.W., Zhou, Z.Q., Yang, H.X., Wei, C.X., Wan, Y.Y., Wang, X.J., Bai, J.G.: Glucose application protects chloroplast ultrastructure in heat-stressed cucumber leaves through modifying antioxidant enzyme activity. - Biol. Plant. 59: 131-138, 2015.

Hwang, S.Y., Lin, H.W., Chern, R.H., Lo, H.F., Li, L.: Reduced susceptibility to waterlogging together with high-light stress is related to increases in superoxide dismutase and catalase activities in sweet potato. - Plant Growth Regul. 27: 167$172,1999$.

Jia, K., Chen, G.: Torrance of different eggplant varieties at seedling stage to high temperature stress. - Chin. J. appl. Ecol. 24: 398-401, 2005.

Jiang, Y., Huang, B.: Effect of calcium on antioxidant activities and water relations associated with heat tolerance in two cool-season grasses. - J. exp. Bot. 52: 341-349, 2001.

Khan, M.I.R., Iqbal, N., Masood, A., Per, T.S., Khan, N.A.: Salicylic acid alleviates adverse effects of heat stress on photosynthesis through changes in proline production and ethylene formation. - Plant Signal Behav. 8: e26374, 2013.

Kim, S.J., Yu, D.J., Kim, T.C., Lee, H.J.: Growth and photosynthetic characteristics of blueberry (Vaccinium corymbosum cv. Bluecrop) under various shade levels. - Sci. Hort. 129: 486-492, 2011.

Klein, B.P., Perry, A.K.: Ascorbic acid and vitamin A activity in selected vegetables from different geographical areas of the United States. - J. Food Sci. 47: 941-945, 1982.

Li, D.M., Nie, Y.X., Zhang, J., Yin, J.S., Li, Q., Wang, X.J., Bai, J.G.: Ferulic acid pretreatment enhances dehydrationstress tolerance of cucumber seedlings. - Biol. Plant. 57: 711-717, 2013.

Lin, S.H., Liu, Z.J., Xu, P.L., Fang, Y.Y., Bai, J.G.: Paraquat pre-treatment increases activities of antioxidant enzymes and reduces lipid peroxidation in salt-stressed cucumber leaves. - Acta Physiol. Plant. 33: 295-304, 2011.

Pang, Y., Huang, B.R., Xu, L.X., Li, Z.: Heat stress effects on osmotic potential, membrane fatty acid composition and lipid peroxidation content of two kentucky bluegrass cultivars differing in drought tolerance. - Acta hort. sin. 40: 971-980, 2013.

Rimando, A.M., Pan, Z., Polashock, J.J., Dayan, F.E., Mizuno, C.S., Snook, M.E., Liu, C.J., Baerson, S.R.: In planta production of the highly potent resveratrol analogue pterostilbene via stilbene synthase and $O$-methyltransferase co-expression. - Plant Biotechnol. J. 10: 269-283, 2012.

Rivero, R.M., Ruiz, J.M., García, P.C., López-Lefebre, L.R., Sánchez, E., Romero, L.: Resistance to cold and heat stress: accumulation of phenolic compounds in tomato and watermelon plants. - Plant Sci. 160: 315-321, 2001.

Sairam, R.K., Rao, K.V., Srivastava, G.C.: Differential response of wheat genotypes to long term salinity stress in relation to oxidative stress, antioxidant activity and osmolyte concentration. - Plant Sci. 163: 1037-1046, 2002.

Sevgi, K., Tepe, B., Sarikurkcu, C.: Antioxidant and DNA damage protection potentials of selected phenolic acids. Food Chem. Toxicol. 77: 12-21, 2015.

Sun, S., Li, P.M., Liu, Q.Z., Ga., H.Y.: Response of photosynthesis to some environmental factors of high-bush blueberry cultivars. - Acta hort. sin. 34: 64-70, 2007.

Vinocur, B., Altman, A.: Recent advances in engineering plant tolerance to abiotic stress: achievements and limitations. Curr. Opin. Biotechnol. 16: 123-132, 2005.

Wahid, A., Gelani, S., Ashraf, M., Foolad, M.R.: Heat tolerance in plants: an overview. - Environ. exp. Bot. 61: 199-223, 2007.

Wan, Y.Y., Zhang, Y., Zhang, L., Zhou, Z.Q., Li, X., Shi, Q., Wang, X.J., Bai, J.G.: Caffeic acid protects cucumber against chilling stress by regulating antioxidant enzyme activity and proline and soluble sugar contents. - Acta Physiol. Plant. 37: 1706, 2015.

Wang, H., Provan, G.J., Helliwell, K.: Determination of rosmarinic acid and caffeic acid in aromatic herbs by HPLC. - Food Chem. 87: 307-311, 2004.

Xu, P.L., Guo, Y.K., Bai, J.G., Shang, L., Wang, X.J.: Effects of long-term chilling on ultrastructure and antioxidant activity in leaves of two cucumber cultivars under low light. Physiol. Plant. 132: 467-478, 2008.

Xue, T., Hartikainen, H., Piironen, V.: Antioxidative and growth-promoting effect of selenium on senescing lettuce. Plant Soil 237: 55-61, 2001.

Yemm, E.W., Willis, A.J.: The estimation of carbohydrates in plant extracts by anthrone. - Biochem. J. 57: 508-514, 1954.

Yu, K.D., Zhu, K.L., Ye, M.J., Zhao, Y.P.: Heat tolerance of highbush blueberry is related to the antioxidative enzymes and oxidative protein-repairing enzymes. - Sci. Hort. 198: 36-43, 2016.

Yun, B.W., Huh, G.H., Kwon, S.Y., Lee, H.S., Jo, J.K., Kwak, S.S.: Antioxidant enzymes in Nicotiana cells containing an Ipomoea peroxidase gene. - Phytochemistry 48: 1287-1290, 1998.

Zhang, J., Li, D.M., Sun, W.J., Wang X.J., Bai, J.G.: Exogenous p-hydroxybenzoic acid regulates antioxidant enzyme activity and mitigates heat stress of cucumber leaves. - Sci. Hort. 148: 235-245, 2012. 